\title{
Breeding ecology of the endemic Black Lark Melanocorypha yeltoniensis on natural steppe and abandoned croplands in post-Soviet Kazakhstan
}

\author{
Thomas K. Lameris ${ }^{1,2}$ (D) Thijs P. M. Fijen ${ }^{2}$. \\ Ruslan Urazaliev $^{3} \cdot$ Genrietta Pulikova $^{3} \cdot$ Paul F. Donald ${ }^{4}$. \\ Johannes Kamp ${ }^{4,5}$
}

Received: 20 April 2015/Revised: 19 November 2015/Accepted: 10 December 2015/ Published online: 30 January 2016

(C) The Author(s) 2016. This article is published with open access at Springerlink.com

\begin{abstract}
Since the collapse of the Soviet Union in 1991, the abundance and distribution of many central Asian steppe birds have been affected by changes in agricultural land management, such as the abandonment of large areas of cropland and changing grazing patterns. However, the underlying population processes that drive patterns of abundance and distribution are poorly understood. We compared the population ecology of the Black Lark Melanocorypha yeltoniensis on natural steppe and abandoned cropland. Between 2009 and 2013, we used distance sampling to quantify Black Lark population density, monitored 220 nests to assess reproductive performance, and modelled habitat selection at several scales. Arthropod food availability was compared using pitfall traps. Mean population densities were three times higher on abandoned cropland compared to those in steppe, and varied with time since abandonment. Nest survival rates were significantly lower on abandoned cropland compared to steppe, probably due to higher predation pressure. Chick growth rates were also lower on abandoned cropland, despite higher insect availability in this habitat. Habitat selection was strongly influenced by grazing intensity
\end{abstract}

Communicated by Didem Ambarl1.

Electronic supplementary material The online version of this article (doi:10.1007/s10531-015-1041-2) contains supplementary material, which is available to authorized users.

Thomas K. Lameris

thomaslameris@gmail.com

1 Department of Animal Ecology, Netherlands Institute of Ecology (NIOO), Droevendaalsesteeg 10, 6700 AB Wageningen, The Netherlands

2 Plant Ecology and Nature Conservation Group, Wageningen University, Droevendaalsesteeg 3, 6708 PB Wageningen, The Netherlands

3 Association for the Conservation of Biodiversity in Kazakhstan (ACBK), 18 Beibitshilik Street, Office 406, Astana, Kazakhstan 010000

4 RSPB Centre for Conservation Science, RSPB, The Lodge, Sandy, Bedfordshire SG19 2DL, UK

5 Institute of Landscape Ecology, University of Münster, Heisenbergstr. 2, 48149 Münster, Germany 
and vegetation structure. We suggest that Black Larks are generally attracted to abandoned cropland because of its suitable vegetation structure and higher food availability. The results of a fecundity model suggested that the number of breeding attempts on abandoned cropland necessary to produce the same number of fledglings as one nesting attempt in steppe habitat was 2.04 in 2011 and 3.62 in 2013. However, a phenological analysis revealed that there were only two peaks in first egg dates, making more than two re-nesting attempts per year unlikely. Therefore, abandoned cropland could, at least in some years, be an ecological trap for the species. Our results illustrate that the effects of land-use change on animal populations should not only be assessed using species densities, but also incorporate detailed demographic analyses. If current densities in steppe habitat corresponded to maximum carrying capacity, overall population densities of Black Larks are likely to decline in the near future as availability of abandoned cropland as nesting habitat is currently decreasing.

Keywords Land-use change - Grazing - Habitat selection - Farmland birds · Ecological trap $\cdot$ Sink $\cdot$ Fecundity

\section{Introduction}

Agricultural intensification and expansion due to increasing world food demand are important drivers of global species endangerment (Green et al. 2005). Natural grasslands and low-input farmland are particularly threatened by changes in agricultural management, as are the species they harbour (Dengler et al. 2014). In Europe, populations of farmland bird species are in rapid decline, and agricultural intensification has been identified as the main cause (Donald et al. 2006). Large numbers of open country birds still thrive on the Eurasian steppes in Eastern Europe and Central Asia. After the dissolution of the Soviet Union in 1991, these areas have been subject to large-scale land-use changes, which have resulted in responses in bird populations (Kamp et al. 2011).

During the 1990s, livestock numbers across Kazakhstan collapsed due to socioeconomic transformation (Robinson and Milner-Gulland 2003), grazing patterns changed and intensive grazing became restricted to areas immediately surrounding villages (Kamp et al. 2012). Large areas of cropland were abandoned as agricultural subsidies were withdrawn (Suleimenov and Oram 2000). By 2013, nearly $40 \%$ of the formerly used cropland in Kazakhstan (ca. 14 million ha) were still abandoned across the steppe zone compared to in the year 1990 (Kazakhstan State Statistics Agency 2014). Next to steppe habitat, abandoned cropland supports the highest densities of steppe and farmland birds in the Kazakh steppe zone, and the abandonment of farmland has probably contributed to population increases in several species (Kamp et al. 2011). However, Kazakhstan's economic situation has been improving since the year 2000, and formerly abandoned cropland is increasingly recultivated (Petrick et al. 2013; Kraemer et al. 2015). This leads to new habitat loss for steppe birds (Kamp et al. 2011).

We used the Black Lark (Melanocorypha yeltoniensis), a bird endemic to the steppe zone of Europe and Central Asia, as a model species to understand better how steppe birds respond to changes in land-use. Although declining in western Kazakhstan and southwest Russia (Birdlife International 2004), the species remains relatively common in the steppe region of central Kazakhstan (Kamp et al. 2011), where populations have been influenced 
by changes in land use (Kamp et al. 2012). We aimed to understand the populationecological processes that influence distribution and abundance of steppe birds in natural and altered habitat. We therefore compared population densities, food availability, habitat selection, chick growth rates and nest survival rates of the Black Lark in steppe and abandoned farmland.

\section{Methods}

\section{Study species}

The Black Lark is a ground-nesting passerine that is found in a variety of habitat types across the steppe zone, including agricultural habitats. It is listed as critically endangered on the European Red List due to strong declines in some areas and the apparently very small size of the remaining population in Russia (BirdLife International 2015a). This status seems however questionable, as the European part of Kazakhstan (where Black Larks are still common) was excluded from the assessment. More than $95 \%$ of the species' population occur in the Asian part of Kazakhstan, where the species can be abundant in places, and it is consequently not globally threatened. There is no global population estimate available, but in Kazakhstan the total population is likely to number hundreds of thousands or even millions of birds due to the very large range (BirdLife International 2015b). The species prefers vegetation mosaics with Stipa and Festuca grasses and Atriplex and Sueda forbs (Glutz von Blotzheim and Bauer 1985). During the breeding season, Black Larks feed mainly on insects, particularly beetles (Volchanetskii 1954). In autumn, females migrate up to $2000 \mathrm{~km}$ to wintering grounds in south Kazakhstan, Uzbekistan and Ukraine (Glutz von Blotzheim and Bauer 1985). Males are resident and spend the winter in flocks on the breeding grounds (Urazaliev et al. 2012), where they feed on seeds of Stipa spp. and other steppe grasses, and spilled grain (Krivitskii 2007). Sex ratios appear to be strongly skewed towards males (Volchanetskii 1954; Krivitskii 2007).

\section{Study area}

We combined data collected in the course of several projects on steppe birds in the TengizKorgalzhyn depression about $120 \mathrm{~km}$ SW of Kazakhstan's capital Astana near the village of Korgalzhyn (N50 $\left.34^{\prime}, \mathrm{E} 70^{\circ} 00^{\prime}\right)$. The area is largely flat, elevation above sea level is ca. $350 \mathrm{~m}$. The native vegetation is dominated by the grasses Stipa lessingiana and $S$. capillata, Festuca sulcata and several species of wormwood Artemisia. The climate is strongly continental with an annual mean temperature of $4.1{ }^{\circ} \mathrm{C}$ (range -40.6 to $+40.1^{\circ} \mathrm{C}$ ). Precipitation varies greatly between years with an average of $335 \pm 66 \mathrm{SD} \mathrm{mm}$ and a range 248-494 mm for the period 2005-2014 (weather data source: http://rp5.ru).

In 2009, data on Black Lark densities were collected across agricultural habitats and steppe over an area of ca. $20,000 \mathrm{~km}^{2}$. Line transects placed using a systematic sampling design with transects spaced $2 \mathrm{~km}$ apart were walked on arable wheat fields $(\mathrm{n}=26$ transects), abandoned cereal fields (covering a temporal gradient of 1 to 18 years since abandonment, $\mathrm{n}=56)$, Agropyron grass fields sown for fodder $(\mathrm{n}=25)$, and natural steppe (i.e. natural Stipa-Festuca-grassland that has never been ploughed and is currently ungrazed or grazed with extremely low stocking densities, henceforth termed 'steppe', $\mathrm{n}=64$ ). Arable lands (cropland and fodder grass fields) were surveyed within four former 
Soviet state farms, now run by private companies. As no steppe areas were available within the state farms, we selected an area of steppe about $60 \mathrm{~km} \mathrm{SW}$ of Korgalzhyn (and with $639 \mathrm{~km}^{2}$ of similar size to the state farms). This site is situated entirely within the TengizKorgalzhyn nature reserve where natural grazers are still present, including a herd of ca. 2000 Saiga antelopes (Saiga tatarica). In 2011 and 2013, data on nest survival, chick growth rates, habitat selection and arthropod abundance were collected in a smaller study area centered on the village of Korgalzhyn (ca. 14,000 ha of steppe and agricultural habitats). The northern part of the area is dominated by (largely abandoned) wheat and fodder grass fields. At the time of the study, the area was grazed by a herd of ca. 1000 horses and several hundred sheep and cattle, kept for meat and dairy production. The southern part of the study area comprises mainly steppe that was never ploughed and has long been used for low-intensity grazing. At the time of the study, it supported approximately 300 horses, 100 cattle and 100 sheep. Saiga occur only sporadically and in very small flocks in the smaller study area, so their grazing impact is assumed to be insignificant.

\section{Surveys}

We counted Black Larks along line transects of 500 m length, using a systematic sampling design with transects spaced $2 \mathrm{~km}$ apart. Transects were walked in the breeding season between 5 May and 23 May 2009 and repeated between 25 May and 13 June 2009. Surveys were conducted from dawn until 10 am, after which bird activity declined markedly. Distance sampling was used to account for varying detectability between habitats and sexes (Buckland et al. 2001). Where several Black Larks were seen flying together, they were treated as a cluster for distance sampling analyses. We allocated all observations to distance bands of $0-5 \mathrm{~m}, 5-10 \mathrm{~m}, 10-25 \mathrm{~m}, 25-50 \mathrm{~m}, 50-100 \mathrm{~m}, 100-200 \mathrm{~m}$ and 200-500 m. We used laser range finders (Bushnell Scout 1000) to calibrate distance estimation. To assess whether densities varied between years, we repeated transect counts at 74 randomly placed transects (41 on abandoned cropland and 33 in steppe) in the smaller study area in 2011 using the same methods as described above.

\section{Nest monitoring}

We searched for Black Lark nests from 28 April until the end of June in 2011 and 2013. Nests were found by driving and walking transects on abandoned cropland, fodder grass fields and steppe, thereby flushing incubating females ( $82 \%$ of all found nests), or by following birds that carried nesting material or food for chicks $(18 \%)$. We recorded nest locations with a GPS unit. We measured the length and width of all eggs found during the incubation stage with calipers to the nearest $0.1 \mathrm{~mm}$, and weighed them with a portable balance to the nearest $0.1 \mathrm{~g}$. Every third day, we revisited the nests to record nest contents and status. Visits to nests of ground-nesting birds have been shown in a robust meta-analysis to have no or even a positive influence on nest survival rates (Ibáñez-Álamo et al. 2012). Nevertheless, precautions were taken to avoid attracting predators to the nest (short visits on a minimum number of occasions, one visitor, no insect repellent worn). Fledging was defined as the point when chicks left the nest. We recorded nests as successful if at least one chick fledged, indicated by a flattened nest margin and scattered chick droppings around the nest around the expected fledging date (Donald et al. 2002).

In 2011, we collected data in the field on chick growth rates as measured by tarsus length and body weight. Chicks were weighed on an electronic balance to the nearest $0.1 \mathrm{~g}$, 
and the tarsus length was measured on at least two occasions between the eggs hatching and the chicks leaving at around 11 days. Chicks were individually marked on their legs with an indelible marker pen to allow later identification.

Nests were classified as depredated when found empty before the observed or predicted hatching date (for prediction method see below), or when the lining was removed and egg shell fragments were found. Predation of chicks was assumed and the nest recorded as unsuccessful when chicks disappeared from the nest before the age of 10 days (the observed minimum age of leaving the nest in our study), when no chick droppings were found around the nest, and the nest margin was not flattened. Trampling by livestock was assumed to have happened where crushed eggs and yolk or dead, injured chicks were found in the nest, and hoof prints were visible in and around the nest. When the eggs were cold during a number of subsequent nest visits or dead chicks were encountered, we assumed nest abandonment, caused e.g. by the death of the female through predation (Donald et al. 2002). Failure, hatching and fledging (where not observed) were assumed to have happened at the midpoint between the two last visits (Mayfield 1961).

\section{Recording of nest and foraging habitat parameters}

A total of 13 of vegetation parameters, livestock dung cover and litter cover were recorded within a vegetation quadrat of $2 \times 2 \mathrm{~m}$ centered on each nest in 2011 and 2013 (Table 1). We recorded these parameters as they have been shown to be influential in previous habitat selection studies in the area, and are suitable to describe the main differences between

Table 1 Means and associated standard errors for all habitat parameters recorded in 2011 at feeding sites and nests of Black Larks, and random points representing availability

\begin{tabular}{|c|c|c|c|c|}
\hline \multirow[t]{2}{*}{ Variable } & \multicolumn{2}{|l|}{ Nest site selection } & \multicolumn{2}{|c|}{ Foraging site selection } \\
\hline & Nests $(\mathrm{n}=98)$ & $\begin{array}{l}\text { Random points } \\
(\mathrm{n}=98)\end{array}$ & $\begin{array}{l}\text { Foraging } \\
\text { sites } \\
(n=64)\end{array}$ & $\begin{array}{l}\text { Random points } \\
(\mathrm{n}=100)\end{array}$ \\
\hline Cover of bare ground $(\%)$ & $30.29 \pm 2.13$ & $40.54 \pm 2.74$ & $64.67 \pm 2.77$ & $40.54 \pm 2.71$ \\
\hline Cover of animal dung $(\%)$ & $4.14 \pm 0.26$ & $1.02 \pm 0.26$ & $0.42 \pm 0.13$ & $1.02 \pm 0.25$ \\
\hline Cover of shrubs $(\%)$ & $0.67 \pm 0.52$ & $1.22 \pm 0.69$ & & \\
\hline Cover of grasses $(\%)$ & $39.15 \pm 2.72$ & $25.22 \pm 2.74$ & $0.91 \pm 0.31$ & $25.22 \pm 2.71$ \\
\hline Cover of Stipa $(\%)$ & $9.26 \pm 1.94$ & $8.66 \pm 1.72$ & & \\
\hline Cover of Festuca (\%) & $5.02 \pm 0.99$ & $5.48 \pm 1.22$ & & \\
\hline Cover of woody Artemisia (\%) & $6.2 \pm 0.83$ & $4.72 \pm 0.78$ & & \\
\hline Cover of weedy Artemisia (\%) & $4.21 \pm 1.04$ & $6.28 \pm 1.54$ & & \\
\hline Cover of Agropyron seed grass ( $\%$ ) & $20.91 \pm 2.54$ & $5.57 \pm 1.34$ & $1.52 \pm 0.61$ & $5.57 \pm 1.32$ \\
\hline Cover of annual plants $(\%)$ & & & $32.5 \pm 2.99$ & $2.4 \pm 0.38$ \\
\hline Cover of litter $(\%)$ & $8.79 \pm 0.89$ & $11.64 \pm 1.66$ & $1.92 \pm 0.71$ & $11.64 \pm 1.64$ \\
\hline Maximum vegetation height $(\mathrm{cm})$ & $347.94 \pm 11.88$ & $263.03 \pm 19.55$ & $64.97 \pm 3.15$ & $263.24 \pm 19.35$ \\
\hline Modal vegetation height $(\mathrm{cm})$ & $116.68 \pm 5.32$ & $90.38 \pm 7.25$ & & \\
\hline Horse dung density (piles, counted) & $14.06 \pm 0.79$ & $12.34 \pm 0.94$ & & \\
\hline Cattle dung density (piles, counted) & $4.11 \pm 0.55$ & $3.44 \pm 0.55$ & & \\
\hline Sheep dung density (piles, counted) & $0.03 \pm 0.02$ & $0.2 \pm 0.13$ & & \\
\hline
\end{tabular}


steppe and abandoned cropfields. To estimate domestic livestock grazing intensity, piles of horse, cattle and sheep dung were counted along a strip transect of $50 \mathrm{~m}$ length and $2 \mathrm{~m}$ width along a random bearing, centered on each nest, shortly after the nest was found. The count of dung piles was summed up across all grazing animals. Using dung as a grazing intensity proxy does not allow to quantify grazer density, but it provides a good index of grazing intensity as dung production is correlated with grazer activity (Stumpp et al. 2005; Manthey and Peper 2010), although this relationship might differ between different livestock. We minimized bias, resulting from herbivore behaviour to forage and defecate at different places, by counting dung along a strip transect and not at sample points.

We aimed to compare used sites vs. available sites in a nest site selection analysis. Therefore, in 2011 we collected data on habitat parameters at random points characterising availability and compared them to the parameters recorded at the nests in 2011, pairing random points and nests. The mean distance between two nests was $247 \mathrm{~m}( \pm 77$ $\mathrm{SE})$ in the northern part of the study area and $382 \mathrm{~m}( \pm 76 \mathrm{SE})$ in the southern part, therefore we selected points in a fixed distance of $100 \mathrm{~m}$ from the nest, in a random bearing. We assumed that points within $100 \mathrm{~m}$ would fall within the territory of the respective nest's male and therefore be available predominantly to the pair of the respective nest.

To collect information on foraging habitat selection, we stopped at every second bird observed foraging on 4 days in May and June 2011 across the study area, and covering steppe $(\mathrm{n}=34$ birds) and abandoned cropland $(\mathrm{n}=30)$. At the foraging spot, we recorded habitat parameters based on hypotheses of potentially influential variables (Table 1). These parameters were then compared to those recorded in the same year at randomly selected points in steppe and on abandoned cropland $(n=50$ points in each habitat).

\section{Arthropod sampling}

To compare food availability for Black Larks on abandoned cropland and steppe, we placed pitfall traps at 23 random locations (10 on abandoned cropland, 13 in steppe, proportional to the area of each habitat type in the smaller 2011/2013 study area). At each random location, five traps were set along a transect of $40 \mathrm{~m}$ length, with $10 \mathrm{~m}$ spacing between the traps. We used cylindrical plastic cups of $6 \mathrm{~cm}$ rim diameter and $10 \mathrm{~cm}$ height that were sunk into the ground so that their rim was flush with the top of the surrounding substrate. A 50:50 mix of car cooling liquid (containing mostly ethanol and glycerol) and water was used as preservative. Traps were covered with square hardboard pieces raised on four large nails to keep small vertebrates out of the traps. Traps were operational between 25 May and 25 June 2011, covering the peak lark nestling period when most food is collected. During this period, the traps were emptied after days with heavy rains to prevent trap overflow and dilution of the preservative. For analysis, the contents of all five traps per random location were pooled to avoid pseudo-replication. Arthropods were stored in $80 \%$ ethanol, identified to order, or where possible, family and genus. No size-based filtering was applied. The arthropods were then assigned to five size classes $(0-1 \mathrm{~mm}, 2-5 \mathrm{~mm}$, 6-10 $\mathrm{mm}, 11-20 \mathrm{~mm}$ and $20-50 \mathrm{~mm}$ ), and their number per trap and per genus or family was multiplied with a mean body mass taken from the regressions for terrestrial invertebrates in Sabo et al. (2002): 1, 2.5, 10, 80 and $200 \mathrm{mg}$ for the five size classes. The bodymass values over all arthropods were finally summed up across size classes to obtain a genus-/family-specific biomass estimate per trap. 


\section{Data analysis}

\section{Distance sampling}

We estimated population densities from the transect data collected in 2009 and 2011 using the model of Royle et al. (2004), implemented in package 'unmarked' (Chandler 2013) in R 3.0.2 (R Development Core Team 2015). We fitted habitat as a covariate to calculate habitat-specific density estimates. We assessed half-normal and hazard-rate shaped detection functions and selected the best-performing model using Akaike's Information Criterion corrected for small sample size $\left(\mathrm{AIC}_{\mathrm{C}}\right)$. Parametric $95 \%$ confidence intervals were derived using bootstrapping. Female Black Larks were difficult to detect due to their secretive behaviour in the breeding season, and we had enough detections to model female density separately only in 2009.

\section{Nest survival analysis}

Nest survival often varies with nest age or stage (Rotella et al. 2004), hence first egg dates were estimated in several ways. Where the hatching date was known (hatching of chicks was observed), the mean length of the incubation and laying periods $(10.8+3$ days in $2011, \mathrm{n}=10,11.6+3$ days in $2013, \mathrm{n}=7$ ) were subtracted from this date. The same was done for nests that hatched between two successive nest visits, assuming hatching to have occurred at the midpoint between these visits. Hatching date was predicted in a similar fashion, by adding the mean length of incubation and laying periods to first egg dates for nests for which this was known $(n=53)$. When nests were found that contained chicks, chick age was estimated from morphological features. In 2011, when chick biometrics were taken, chick age was estimated from a regression of weight and tarsus length against time since hatching, the latter based on repeated measurements of chicks of known age $(n=123$ measurements of 49 chicks from 17 nests, Fijen et al. 2015). Where the age estimates differed, the mean of those from the tarsus regression and the weight regression were used. Hatching date was then back-calculated and first egg dates estimated as described above. For nests failing at the egg stage, first egg dates were calculated using egg density from a linear regression of egg density on age from a number of nests of known age $\left(\mathrm{R}^{2}=0.69\right.$, Fijen et al. 2015). This was usually accurate to within 2 days. Egg density was estimated as (length $\times$ width $^{2} \times 0.51$ )/weight (volume estimate after Hoyt 1979). A number of nests failed before the eggs were measured, but simply excluding these nests from age-specific nest-survival models would have positively biased nest survival rates. We therefore assumed that when first found, the eggs in these nests were the same age as the average age of eggs at time of first finding across known-age nests in the same year, and used this year-specific 'time-to-find' estimate as the basis of estimating first egg date from subsequent observations.

Daily nest survival was estimated using a maximum likelihood approach implemented in program MARK (White and Burnham 1999). We modelled a binary nest outcome $(0=$ success, $1=$ failure) with exposure days fitted as the binomial denominator in a Generalised Linear Model with a binomial error distribution and logit-link (Rotella et al. 2004). Program MARK was interfaced via the 'RMark' package (Laake and Rexstad 2008) in R 3.0.2 (R Development Core Team 2015). This modelling framework allows testing for time-dependent survival and seasonal patterns in survival. As we were particulary interested in variation between years and habitats, we included year and habitat as fixed effects. 
Black Larks often assemble animal (mostly horse) dung large into 'pavements' that surround their nest. These structures likely buffer nest temperature extremes and prevent the nest from being trampled by livestock (Fijen et al. 2015). Nest survival could potentially be influenced by the size of the pavements, therefore pavement size (in $\mathrm{cm}^{2}$ ) was fitted as a covariate. Vegetation height at the nest was also used as a covariate to assess whether nest survival varied with vegetation structure at the nest. Additionally, we fitted the background dung density (number of dung piles along the $50 \mathrm{~m}$-transect) as a measure of grazing pressure. Models containing combinations of the variables were compared using Akaike's Information Criterion for small sample sizes $\left(\mathrm{AIC}_{c}\right.$, Burnham and Anderson 2002). A maximum of four variables in the same model were allowed for reasons of parsimony, correlated variables (Spearman's $r>0.7$ ) fitted alternatingly. An automated procedure (function 'dredge' implemented in R package 'MuMIn', Barton 2012) was used for this. Models within $2 \mathrm{AIC}_{\mathrm{C}}$ units of that with the smallest $\mathrm{AIC}_{\mathrm{C}}$ were considered as receiving equal support from the data.

As there was more than one model with $\Delta \mathrm{AIC}_{\mathrm{C}}<2$, we averaged parameter estimates of all models following the approach of Burnham and Anderson (2002) and calculated standard errors as the square-root of the unconditional variance estimator. Relative variable importance $w_{+}(j)$ was calculated as the sum of Akaike weights over all models including the respective explanatory variable (Burnham and Anderson 2002). All continuous variables were z-transformed.

\section{Fecundity model}

There were large differences in nest survival between habitats, therefore we attempted to assess whether birds might be able to compensate for low nest survival by undertaking more nesting attempts. Following Etterson et al. (2011), we modeled how many nesting attempts would be needed in habitats with low nest survival to produce the same number of fledglings as in a single nesting attempt in habitat with high nest survival. Fledging was defined as the point when chicks leave the nest, although lark chicks often leave the nest before they are able to fly, but following chicks after they left the nest proved impossible as they were extremely secretive. We modelled fecundity (the reproductive output as the total number of fledglings, $\mathrm{F}$ ) as $\mathrm{F}=\mathrm{Y} * \mathrm{~S} * \mathrm{~N}$, in which $\mathrm{Y}$ is the number of young per successful nest raised to fledging (taken from our nest data), $\mathrm{S}$ is the expected probability that a nest fledges at least one fledgling (also termed nest success or overall survival probability), calculated as $S=\mathrm{s}^{\mathrm{a}}$, with $\mathrm{s}$ being daily nest survival rate (taken from our survival analysis) and a the age of the nest at fledging (average length incubation stage + average length chick stage, based on our field data). $\mathrm{N}$ is the number of nesting attempts, for which we took 1 as we were interested in fecundity assuming a single nesting attempt. Because daily nest survival increased as the season progressed, we estimated fecundity for each possible first egg date separately, by calculating $\mathrm{S}$ using the specific daily survival rates $\mathrm{s}$ following this first egg date. For each of these we then calculated the number of nesting attempts needed in habitat with low survival, by dividing the calculated fecundity $\mathrm{F}$ of the habitat with higher survival by the $\mathrm{F}$ of habitat with lower survival.

\section{Chick growth rate estimation}

We used non-linear mixed effects models in package 'lme4' in $\mathrm{R}$ 3.0.2 to assess the influence of habitat on chick weight and tarsus growth rates, following Sofaer et al. (2013). Because chicks leave the nest before the asymptotic weight or tarsus length is reached, we 
replaced the asymptotic term in the three-parameter growth model with a constant reflecting the approximate adult weight $(38 \mathrm{~g})$ or tarsus length $(40 \mathrm{~mm})$ and fitted twoparameter models in which only the growth rate constant and inflection point were estimated (Austin et al. 2011). We fitted different random effects structures, allowing the random effects of nest, chick, or chick-within-nest on the inflection point, the growth constant or both. These nine candidate models also contained the fixed effect of habitat, which was evaluated after the most appropriate random effect terms were identified, following Zuur et al. (2009). The model with the best support was identified using $\mathrm{AIC}_{\mathrm{C}}$ and this was then compared using the 'anova' function to a model with the same random effects structure but without the factor relating to the influence of habitat on growth constant and inflection point.

\section{Nest site and foraging habitat selection}

We identified variables affecting nest site selection using a machine learning approach based on ensembles of classification trees (Random Forest models, Breiman 2001). This approach is useful for small datasets with a larger number of often correlated explanatory variables (Grömping 2009). We used the R package 'randomForest' (Liaw and Wiener 2002) to build a full model containing all recorded predictor variables for both the foraging and nest site selection dataset. The number of classification trees to grow was set to 1500 , with 5 variables randomly sampled at each split. To explore the characteristics of utilised vs. available sites (i.e. nest and foraging sites vs random points) in more detail, we additionally built generalized linear models (GLMs) with a binomial link function (i.e. logistic regression) that included those variables that proved influential in the random forest model. We also included quadratic terms to allow for unimodal relationships. Model calibration and refinement was assessed with Nagelkerke's $R^{2}$ (Nagelkerke 1991), and the discriminative power of the models by calculating the area under the curve (AUC) of receiver operating characteristic (ROC) plots, using implementations in the R packages 'fmsb' (Nakazawa and Nakazawa 2014) and 'pROC'(Robin et al. 2011). Plots of fitted values were produced using the R package 'popbio' (Stubben et al. 2008).

\section{Arthropod biomass}

Arthropod biomass was compared between steppe and abandoned cropland using nonparametric independent 2-group Wilcoxon tests. The cluster of five traps per random point was considered the sampling unit.

\section{Results}

\section{Population densities and sex ratios}

In 2009 and 2011, the density of males and females was on average about three times higher on abandoned cropland than in steppe $(n=1553$ counted males and 72 females in 2009, 512 males in 2011, Fig. 1a, b). Fodder grass fields held up to twice as many male Black Larks as steppe, whereas densities on active cropland were similar to those in steppe (Fig. 1a, b). Within the abandoned cropland, male densities peaked on fields abandoned for about 10 years (Generalised Additive Model, $\mathrm{p}<0.001, \mathrm{df}=4, \quad$ Deviance 
(a)

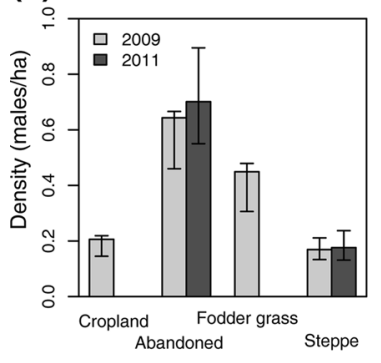

(b)

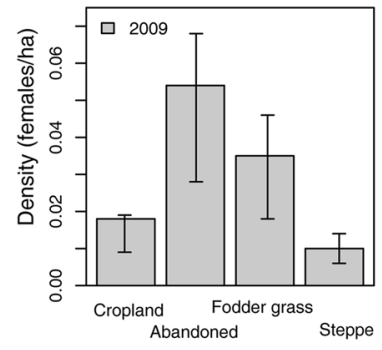

(c)

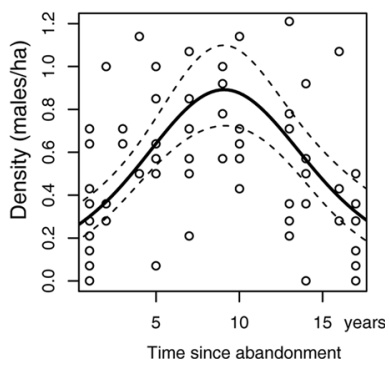

Fig. 1 Densities of Black Lark males (a) and females (b) in steppe, abandoned cropland, fodder grass fields and wheat crops in 2009 and 2011; and densities of Black Lark males in relation to time since abandonment of former arable fields in 2009 (c). In c, a Generalized Additive Model (GAM) relating abundance to time since abandonment is shown (solid line fitted model values, dashed lines upper and lower $95 \%$ confidence limits; cf. text for model statistics)

explained $=31.6 \%$; Fig. 1c). Observed sex ratios in 2009 were strongly male-skewed in all habitats, ranging from 0.875 on abandoned cropland to 0.934 in steppe (mean $0.905 \pm 0.025 \mathrm{SD})$.

\section{Nest survival}

A total of 220 Black Lark nests was found and monitored, 128 in 2011 and 92 in 2013. Of these, 94 were situated on abandoned cropland, 72 in steppe and 54 in fodder grass fields. Daily nest survival for both years combined was 0.939 ( \pm 0.005 standard error (SE), $95 \%$ confidence limit (CL) $0.928-0.948$ ). This is equal to a mean probability of a nest to survive the entire nesting period of 0.207 (CL: 0.155-0.268), using the mean observed incubation period length of 11.2 days ( +3 days for laying) and a mean age of 10.8 days at which chicks leave the nest (own data).

Nest survival increased with the age of the nest, and there was weak support for a seasonal trend in nest survival, with nests initiated later having a lower probability of survival (Table 2). Nest success was much lower in 2013 than in 2011 (Fig. 2). Nests in steppe were much more likely to survive than those on abandoned cropland and fodder grass fields, this trend being consistent across years (Fig. 2). Models containing the amount of animal dung at the nest and vegetation height were within $2 \mathrm{AIC}_{\mathrm{C}}$ units of that with the smallest $\mathrm{AIC}_{\mathrm{C}}$, although the effect size for both variables was rather small and variable importance low. Positive coefficients of the two variables suggested a tendency for nests situated in areas of more dung (independent of habitat) and taller vegetation to survive longer (Table 2).

The main reason for nest failure in all habitats was predation, accounting for $97.1 \%$ of nest failures in 2011 and $84.5 \%$ in 2013. Only two nests were trampled in 2011 and none in 2013, but nine nests were classified as deserted in 2013. At three of these, remains of females were found, corresponding to higher nest predation rates in this year. This suggests that predation of the female on the nest was more likely in these cases than genuine desertion e.g. due to disturbance by the observers (Fig. 2). The lower nest success in 2013 was consistent across habitats and therefore probably resulted from higher predator density or activity compared to 2011 . 


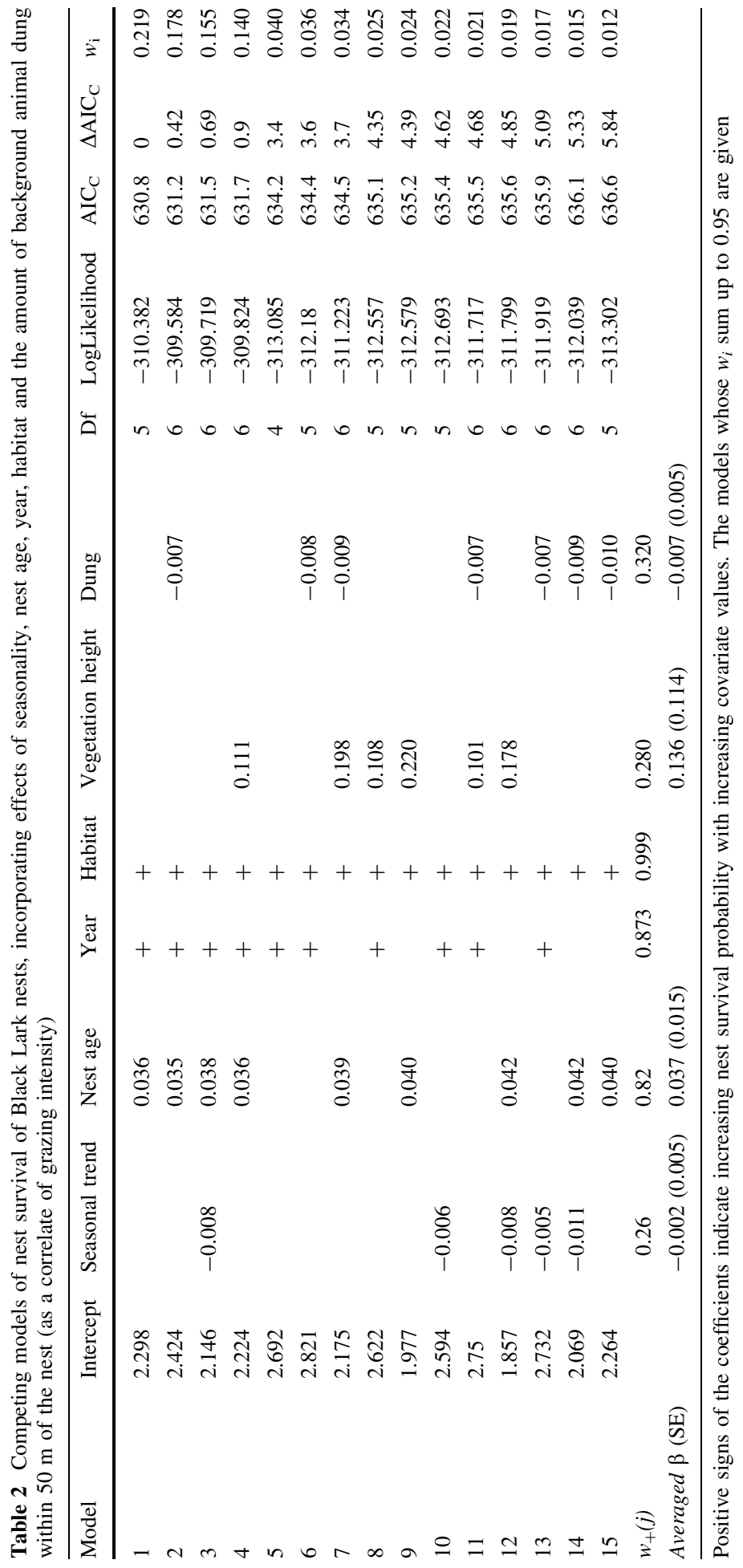



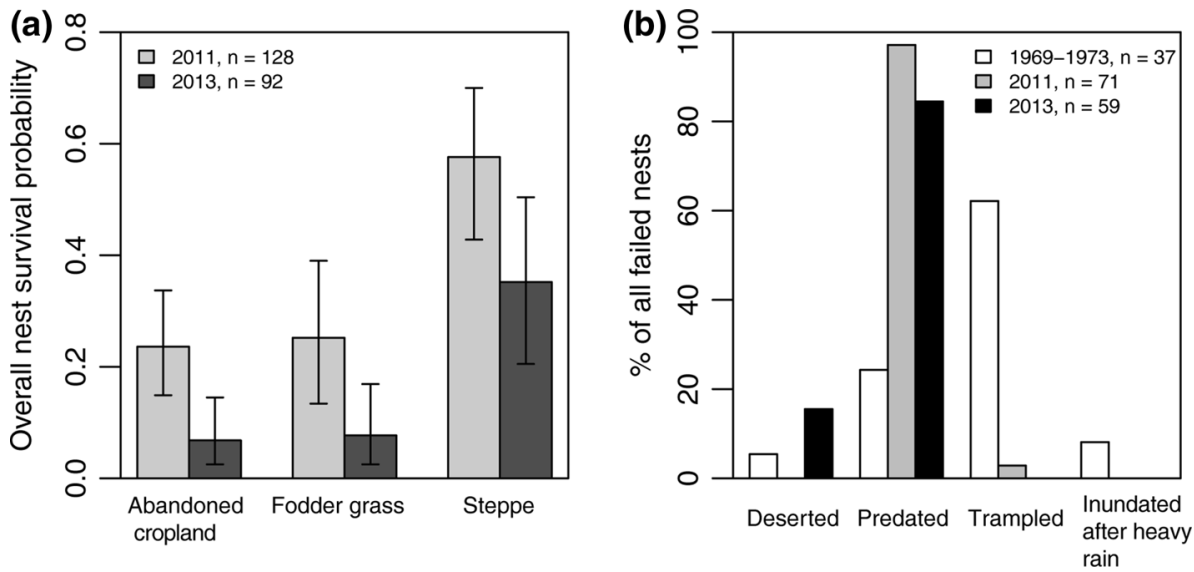

Fig. 2 a Overall probability of a nest surviving from egg laying to the point when the chicks leave the nest (nest success), separated by year and habitat (error bars give standard errors); b causes of nest failure in 2011 and 2013 as percentage of all unsuccessful nests. Data from Moiseev (1980) from 1969-1973 are also given for comparison

\section{Incubation and chick growth parameters}

Mean first egg dates did not differ between habitats (ANOVA, $F_{4,215}=1.17, p=0.32$ ), but the distribution of first egg dates over time for different habitats suggested that there were more re-nesting attempts on abandoned cropland than in other habitats (Fig. 3). The duration of incubation, based on nests with known first egg date, was on average 11.7

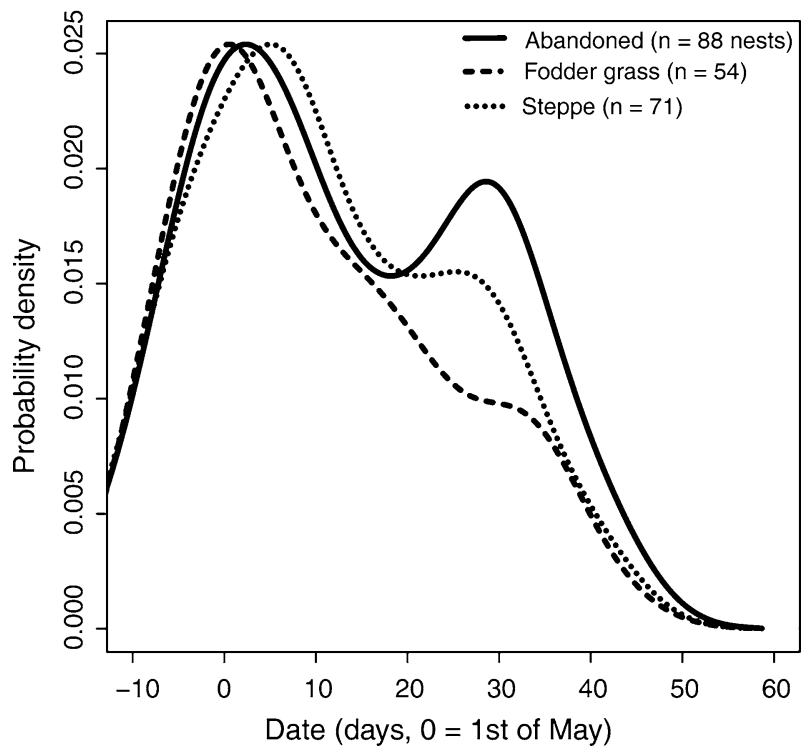

Fig. 3 Distribution of standardized first egg dates (Kernel probability density function, separated for the three main habitats) 
$( \pm 0.98 \mathrm{SD} ; \mathrm{n}=10)$ and $10.8( \pm 0.84 \mathrm{SD} ; \mathrm{n}=7)$ days in 2011 and 2013, respectively. The average period of feeding chicks in the nest was $10.9( \pm 1.31 \mathrm{SD} ; \mathrm{n}=46)$ and $11.8( \pm 1.61$ $\mathrm{SD} ; \mathrm{n}=14$ ) days in 2011 and 2013, respectively.

Mean clutch size was $3.30 \pm 0.61 \mathrm{SD}$ eggs (range $2-5$, median $=3 ; \mathrm{n}=178$ nests). Clutch size did not differ between habitats (Kruskal-Wallis test, $\chi^{2}=0.74$, df $=2$, $p=0.69$; mean clutch size $3.32 \pm 0.59$ on abandoned cropland, $3.26 \pm 0.54$ on fodder grass, $3.33 \pm 0.70$ in steppe, $\mathrm{n}=178$ ). Similarly, the number of chicks hatched per successful nest did not differ between habitats (Kruskal-Wallis test, $\chi^{2}=1.46$, $\mathrm{df}=2$, $p=0.48$; mean number of hatchlings $3.02 \pm 0.71$ on abandoned cropland, $2.85 \pm 0.72$ on fodder grass, $3.04 \pm 0.72$ on steppe, $\mathrm{n}=129$ ).

For models of both chick weight and tarsus growth, the best supported combination of random effects was that with a random effect of nest on both inflection point and growth rate constant. In the case of the model of weight, the model including a binary habitat variable (steppe vs abandoned cropland) received significantly greater support $\left(\Delta \mathrm{AIC}_{\mathrm{C}}=3.25\right)$ than that with the same random effects but without habitat variable ('anova' function, $p<0.05$ ), and the regression parameters indicated a higher growth rate constant for nests in steppe than for nests on abandoned cropland. There was no significant effect of habitat in the models of tarsus growth $(p=0.08)$, and both models were within 2 $\Delta \mathrm{AIC}_{\mathrm{C}}$ units $\left(\Delta \mathrm{AIC}_{\mathrm{C}}=1.69\right)$.

\section{Fecundity}

The mean number of chicks leaving the nest per nesting attempt differed between years and habitats (2011: $1.08 \pm 0.07 \mathrm{SE}$ on abandoned cropland, $1.03 \pm 0.07 \mathrm{SE}$ on fodder grass and $1.93 \pm 0.06 \mathrm{SE}$ in steppe; 2013: $0.54 \pm 0.06 \mathrm{SE}$ on abandoned cropland, $0.52 \pm 0.05$ $\mathrm{SE}$ on fodder grass and $1.38 \pm 0.07 \mathrm{SE}$ in steppe). The number of breeding attempts necessary to produce the same number of chicks as one nesting attempt in steppe was $2.04 \pm 0.09 \mathrm{SE}$ on abandoned cropland and 2.11 $\pm 0.29 \mathrm{SE}$ on fodder grass in 2011 and $3.62 \pm 0.09 \mathrm{SE}$ on abandoned cropland and 3.66 $\pm 0.28 \mathrm{SE}$ on fodder grass in 2013 .

\section{Nest site and foraging habitat selection}

Variables with high importance identified in the Random Forest model were the cover of annual plants and maximum vegetation height in foraging selection, and the cover of animal dung and maximum vegetation height in nest site selection (Fig. 4). All other variables led to mean decreases in the Gini coefficient of $<10 \%$ and were thus not considered useful in classifying recorded presences and absences (Fig. 4). Logistic regression models including the influential variables identified by the Random Forest model were outstanding regarding model calibration and refinement, and had a high power to discriminate between presences and absences (Table 3; Fig. 5).

Swards of annual plants at foraging spots on abandoned cropland were dominated by two species, Alyssum turcestanicum and Lepidium perforatum. Foraging sites in steppe were dominated by Salicornia spp., but Black Larks were also found foraging in taller Stipa-Festuca swards. The signs of the regression coefficients suggested that the probability of a Black Lark selecting an area for foraging increased with increasing cover of annual plants, and decreasing vegetation height (Fig. 4; Table 3). The probability of a nest being present peaked at ca. $40 \mathrm{~cm}$ vegetation height and ca. $10 \%$ cover of animal dung (Fig. 5; Table 3). 


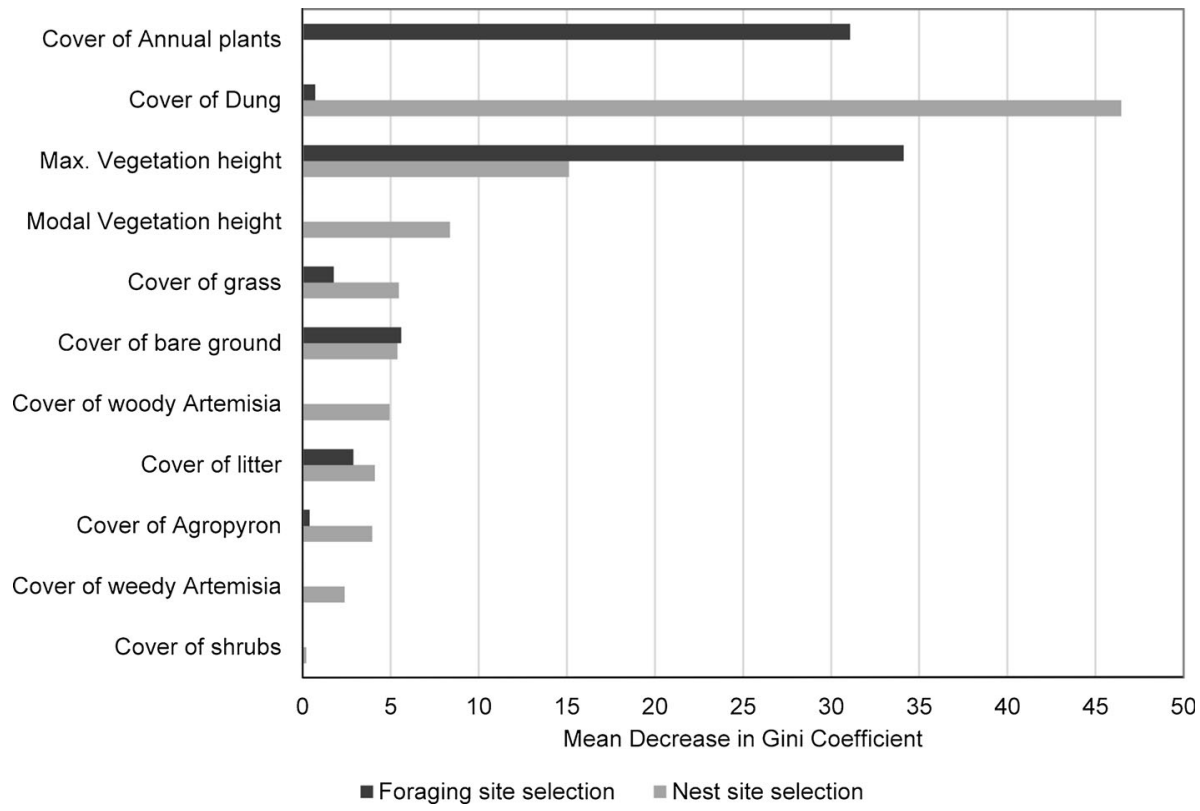

Fig. 4 Variable importance estimates from Random Forest models (total decrease in node impurities from splitting on the variable, averaged over all trees) used to classify Black Lark presences and pseudo-absences in nest and foraging site selection. Estimates are standardized to $100 \%$. 'Cover of dung' relates to dung abundance in the surrounding of the nest site, measured as number of dung piles along a $50 \mathrm{~m}$ - strip transect centered on the nest

Table 3 Binary logistic regression models relating habitat variables to presence-absence data (foraging/ nest sites vs. random points)

\begin{tabular}{|c|c|c|c|c|c|c|}
\hline \multicolumn{2}{|c|}{ Model A: Foraging habitat selection } & \multirow{2}{*}{ Variable } & \multirow{2}{*}{$\beta$} & \multirow{2}{*}{$\frac{\mathrm{SE}}{0.699}$} & \multirow{2}{*}{$\begin{array}{l}\mathrm{Z} \\
1.490\end{array}$} & \multirow{2}{*}{$\frac{P}{0.136}$} \\
\hline & & & & & & \\
\hline Nagelkerke's $R^{2}: 0.876$ & & Cover of Annual Plants & 0.220 & 0.057 & 3.877 & $<0.001$ \\
\hline AUC: 0.987 & & Maximum vegetation height & -0.032 & 0.008 & -4.106 & $<0.001$ \\
\hline \multirow[t]{4}{*}{ Model B: Nest site selection } & \multicolumn{2}{|c|}{ Variable } & $\beta$ & SE & $\mathrm{Z}$ & $P$ \\
\hline & \multicolumn{2}{|c|}{ Intercept } & -9.101 & 1.656 & -5.495 & $<0.001$ \\
\hline & \multicolumn{2}{|c|}{ Cover of animal dung } & 1.619 & 0.244 & 6.641 & $<0.001$ \\
\hline & \multicolumn{2}{|c|}{ Cover of animal dung (squared) } & -0.095 & 0.019 & -4.929 & $<0.001$ \\
\hline Nagelkerke's $R^{2}: 0.744$ & \multicolumn{2}{|c|}{ Maximum vegetation height } & 0.041 & 0.010 & 4.214 & $<0.001$ \\
\hline AUC: 0.949 & \multicolumn{2}{|c|}{ Maximum vegetation height (squared) } & -0.0002 & 0.0003 & -3.787 & $<0.001$ \\
\hline
\end{tabular}

Only those habitat variables were included in the model that resulted in a mean decrease of the Gini coefficient of $>10$ in random forest models (cf. Fig. 4) 


\section{Foraging habitat selection}
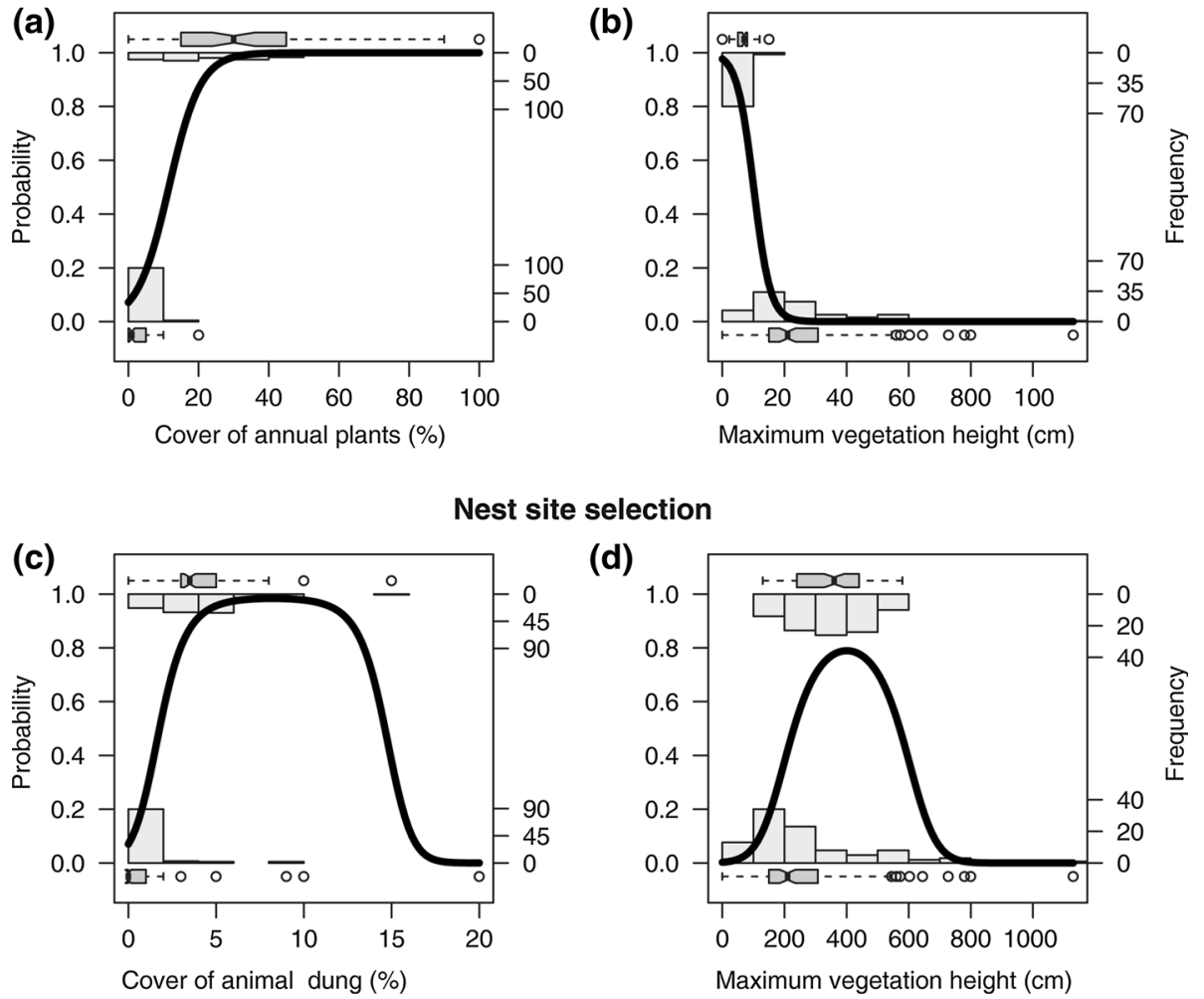

Fig. 5 Plots of univariate logistic regression models comparing Black Lark nest (a, b) and foraging (c, d) sites to random points for the most influential habitat parameters. The line represents the fitted values from the model (probability of a foraging bird or nest being present), the histogram and boxplots show the distribution of the presence and absence raw data

\section{Arthropod biomass and activity-density}

Trap contents were dominated by Arachnida and the insect orders Hemiptera, Coleoptera and Hymenoptera (Formicidae), of which the combined biomass was on average $90.74 \% \pm 1.72$ SE (range: $53.97-100 \%$ ) of all arthropods in a trap. The numbers and biomass of Orthoptera, Homoptera, Lepidoptera and Hymenoptera (other than Formicidae) were insignificant. Total arthropod biomass calculated from activity-density was significantly higher on abandoned cropland compared to steppe (Table 4). It did not differ between abandoned cropland and steppe for Arachnida and Formicidae, but was significantly higher for Coleoptera (beetles), especially pronounced in the Tenebrionidae (darkling beetles) and Cuculionidae (Weevils) on abandoned cropland (Table 4).

\section{Discussion}

In our study, Black Lark densities were about three times higher on abandoned cropland than in steppe in Central Kazakhstan. This pattern was consistent over the study period, and for both sexes. Male densities varied with time since abandonment, suggesting that 
Table 4 Biomass (in mg \pm SD) of insects and Arachnida (insect orders in bold) caught in pitfalls traps, separate for steppe and abandoned cropland

\begin{tabular}{|c|c|c|c|c|c|c|}
\hline & \multicolumn{2}{|c|}{ Steppe } & \multicolumn{2}{|c|}{ Abandoned farmland } & \multirow[t]{2}{*}{$\mathrm{W}$} & \multirow[t]{2}{*}{$\mathrm{P}$} \\
\hline & Mean & SD & Mean & SD & & \\
\hline Total biomass & 1588 & 1406 & 9309 & 19979 & 373.0 & $0.0092 * *$ \\
\hline Arachnida (Spiders, Mites and allies) & 526 & 136 & 340 & 55 & 224.5 & 0.4380 \\
\hline Araneae (Spiders) & 267 & 48 & 330 & 54 & 306.5 & 0.3080 \\
\hline Acari (Mites) & 12 & 9 & 11 & 5 & 294.5 & 0.3840 \\
\hline Hemiptera (True Bugs) & 2 & 1 & 8 & 3 & 362.5 & $0.0066^{* *}$ \\
\hline Coleoptera (Beetles) & 444 & 111 & 1415 & 338 & 421.0 & $0.0003 * * *$ \\
\hline Carabidae (Ground Beetles) & 65 & 30 & 524 & 246 & 332.5 & 0.0931 \\
\hline Tenebrionidae (Darkling Beetles) & 241 & 92 & 596 & 118 & 396.0 & $0.0020 * *$ \\
\hline Curculionidae (Weevils) & 1 & 1 & 29 & 12 & 370.5 & $0.0041 * *$ \\
\hline Beetle larvae & 15 & 9 & 19 & 13 & 264.5 & 0.9057 \\
\hline Hymenoptera: Formicidae (Ants) & 514 & 296 & 7025 & 4518 & 335.0 & 0.098 \\
\hline
\end{tabular}

An independent 2-group Wilcoxon Test was used to compare the means for both habitat types

Significant $P$-values are given in bold and stars indicate the significance level $(* P<0.05$, ** $P<0.01$, *** $P<0.001)$

vegetation succession on abandoned cropland creates optimum conditions for the species around 10 years after abandonment (Fig. 1). There might be several reasons for this pattern. First, the biomass of ground-dwelling arthropods, mainly Coleoptera, was much higher on abandoned cropland than in steppe. Black Larks are known to feed mainly on the same taxonomic groups (Carabidae, Tenebrionidae and Curculionidae) for which the differences in abundance between habitats were most pronounced in our study (Volchanetskii 1954; Ryabov 1967). Black Larks (and other steppe birds) might therefore mainly be attracted by high food availability to abandoned cropland. However, faster nestling growth in steppe habitat suggested that the higher arthropod activity on abandoned cropland was not necessarily indicative of better food availability. Second, while preferred foraging sites of Black Larks had short vegetation, Black Larks preferred taller vegetation for nesting. A small-scale mosaic of short and tall vegetation and bare ground is typical for abandoned cropland, the habitat in which Black Lark densities were highest. The steppe grasslands in our study area were much more uniform as current grazing pressure is low, and are dominated by tall and dense stands of grasses (Online Resource). Vegetation mosaics have been identified as important in habitat selection for other lark species, perhaps because they provide suitable habitat both for nesting and foraging (Seoane et al. 2006; Erdős et al. 2009; Morgado et al. 2010).

Abandoned cropland habitat was preferred by Black Larks, yet nest survival was much lower there compared to steppe. As larks are known to avoid nesting in habitats with high predation risk (Martin 1993; Suhonen et al. 1994), a preference of Black Larks for habitat with low nest survival and thus probably high predation risk might suggest that Black Larks mistake abandoned cropland for high-quality habitat (Remes 2000). This could mean abandoned cropland acts as an ecological trap for Black Larks. Ecological traps are habitats low in quality for reproduction and survival that cannot sustain a population, yet are preferred over other available, high quality habitats (Donovan and Thompson 2001; Battin 2004). The preference for low quality habitat is caused by a mismatch in the cues 
used for habitat selection and habitat quality (Kokko and Sutherland 2001). Ecological traps are typically found in areas with rapid land-use change, where time to adapt to a changing environment is limited and animals make apparent mistakes in habitat selection as they are adapted to their past environments (Remes 2000; Schlaepfer et al. 2002). Ecological trap habitats are thus characterised by a strong preference of the focal species and a low quality for reproduction as compared to surrounding habitats (Battin 2004). Although abandoned cropland appears to be low in quality due to low nest survival, this might be compensated for by larger clutches, more replacement clutches or increased survival rates of fledged chicks. We were unable to estimate post-fledging survival, but found no difference in clutch size between habitats. A comparison of the distribution of first egg dates between habitats indicated that more birds undertook a second nesting attempt on abandoned cropland than in other habitats. Our fecundity model suggested that with two nesting attempts on abandoned cropland, birds could in 2011 produce as many fledglings as with one nesting attempt in steppe. In 2013 however, as many as 3.6 nesting attempts would have been needed to produce as many fledglings on abandoned cropland as in steppe. Renesting could thus in some years compensate for low nest survival, as suggested for Skylarks (Alauda arvensis) nesting on set-aside on UK farmland (Donald et al. 2002), but we present evidence here that this is not the case in every year. As low nest survival might be compensated for, the habitat choice is rather a trade-off than maladaptive behaviour (Battin 2004; Flaspohler et al. 2007). However, renesting is energetically costly and could also decrease adult survival (Morris et al. 2015).

As predation was the main cause of lower nest survival on abandoned cropland, generalist predation intensity is expected to be higher on abandoned cropland than in steppe. High seed availability from a larger cover of weedy plants could enable high densities of small rodents to prosper (Noguerales et al. 2015). Small rodents themselves can predate bird nests (Pärt and Wretenberg 2002), and also attract larger predators (small mammals and birds of prey) which can in turn switch to bird nest predation when rodent densities decrease (Angelstam et al. 1984). On the other hand, density-dependent processes could play a role, and high densities of nesting Black Larks in abandoned cropland might attract more predators, resulting indeed in density-dependent nest survival (Sinclair and Pech 1996) as has been suggested for Skylarks (Delius 1965; Donald et al. 2002). Also intraspecific competition for resources is an important density-dependent process which could lead to reduced breeding success. When breeding success is so low that total reproduction output becomes insufficient to balance mortality (Pulliam 1998) this turns a habitat into a sink, and can thus be possibly driven by density-dependent nest survival (Watkinson and Sutherland 1995; Remes 2000; Battin 2004; Gilroy and Sutherland 2007). Typically such habitats are attractive sinks, and will still attract immigrants due to erroneously overestimated quality even after having become a sink (Remes 2000; Delibes et al. 2001; Gilroy and Sutherland 2007).

The availability of huge expanses of abandoned cropland as a nesting habitat for Black Larks is a recent phenomenon on the steppes of Kazakhstan, but agricultural habitats have been available for a long time to European open-country birds. Apparently, these habitats are highly attractive for birds and can support higher densities than natural habitats, even though reproductive output may be lower. Switching to human-altered habitats might be opportunistic, as these habitats are quickly to appear but also disappear or become unsuitable as a nesting habitat, for example under intensification of agricultural management (Kleijn et al. 2004). Meanwhile, natural habitats might support lower but more stable densities of birds, acting as sources for the population. In human-altered landscapes such as Western Europe, the disappearance of natural habitats as sources in combination 
with the intensification of management in human-altered habitats, turning these into sinks, could be an important reason for the current decline of open-country birds (Donald et al. 2006; Kleijn et al. 2006).

On the steppes of Kazakhstan, Black Larks densities are likely to decline again on abandoned cropland, as this will either be reclaimed or increase in age and become less suitable for nesting. As long as natural steppe habitat still exist as a source this is not likely to have dramatic effects at a population level, but whether densities in steppe will again increase, and how these changes will influence population size of Black Larks, is difficult to predict. Modelling bird densities under various scenarios would be an insightful exercise to predict future population fluctuations.

Acknowledgments We thank Johanna Karthäuser and Aleksandr Putilin for help with fieldwork. Aleksandr P. Moiseev and Aleksei Timoshenko provided access to Russian-language literature. This work was supported by small grants of the British Ornithologist's Union (BOU), the German Ornithological Society (DO-G), the Ornithological Society of the Middle East and Central Asian (OSME) and Förderkreis Allgemeine Naturkunde-Biologie e.V. (FAN-B). In 2009 and 2011, fieldwork was conducted within the framework of the 'Altyn Dala Initiative' funded by the UK Government's Darwin Initiative (grant reference 18-004). T.P.M.F. received additional funding from a European Union Erasmus Mundus mobility grant while based at the University of Münster. R.U. is funded by the Volkswagen Foundation, project BALTRAK (Project Ref-No. A112025).

\section{Compliance with ethical standards}

Ethical standards Animal handling complied with the ethical standards and the federal law of the Republic of Kazakhstan.

Open Access This article is distributed under the terms of the Creative Commons Attribution 4.0 International License (http://creativecommons.org/licenses/by/4.0/), which permits unrestricted use, distribution, and reproduction in any medium, provided you give appropriate credit to the original author(s) and the source, provide a link to the Creative Commons license, and indicate if changes were made.

\section{References}

Angelstam P, Lindström E, Widén P (1984) Role of predation in short-term population fluctuations of some birds and mammals in Fennoscandia. Oecologia 62:199-208

Austin SH, Robinson TR, Robinson WD, Ricklefs RE (2011) Potential biases in estimating the rate parameter of sigmoid growth functions. Methods Ecol Evol 2:43-51

Bartoń K (2012) MuMIn: multi-model inference. R package. https://cran.r-project.org/web/packages/ MuMIn/MuMIn.pdf Accessed 17 Sep 2015

Battin J (2004) When Good Animals Love Bad Habitats: ecological Traps and the Conservation of Animal Populations. Conserv Biol 18:1482-1491

Birdlife International (2004) Birds in Europe: population estimates, trends and conservation status. Birdlife Int, Cambridge

BirdLife International (2015a) European Red List of Birds. Office for Official Publications of the European Communities, Luxembourg

BirdLife International (2015b) Species factsheet: Melanocorypha yeltoniensis. Birdlife International. http:// www.birdlife.org/datazone/species/factsheet/22717301 Accessed 25 Sep 2015

Breiman L (2001) Random forests. Mach Learn 45:5-32

Buckland ST, Anderson DR, Burnham KP, Laake JL, Borchers DL, Thomas L (2001) Introduction to distance sampling: estimating abundance of wildlife populations. Oxford University Press, Oxford

Burnham KP, Anderson DR (2002) Model selection and multimodel inference: a practical informationtheoretic approach. Springer Science \& Business Media, New York

Chandler R (2013) Distance sampling analysis in unmarked. USGS Patuxent Wildl Res Center, Maryland

Delibes M, Gaona P, Ferreras P (2001) Effects of an attractive sink leading into maladaptive habitat selection. Am Nat 158:277-285 
Delius JD (1965) A Population Study of Skylarks Alauda arvensis. Ibis 107:466-492

Dengler J, Janišová M, Török P, Wellstein C (2014) Biodiversity of Palaearctic grasslands: a synthesis. Agric Ecosyst Environ 182:1-14

Donald PF, Evans AD, Muirhead LB et al (2002) Survival rates, causes of failure and productivity of Skylark. Ibis 144:652-664

Donald PF, Sanderson FJ, Burfield IJ, van Bommel FPJ (2006) Further evidence of continent-wide impacts of agricultural intensification on European farmland birds, 1990-2000. Agric Ecosyst Environ 116:189-196

Donovan TM, Thompson FR (2001) Modeling the ecological trap hypothesis: a habitat and demographic analysis for migrant songbirds. Ecol Appl 11:871-882

Erdős S, Báldi A, Batáry P (2009) Nest-site selection and breeding ecology of Sky Larks Alauda arvensis in Hungarian farmland. Bird Study 56:259-263

Etterson MA, Ellis-Felege SN, Evers D et al (2011) Modeling fecundity in birds: conceptual overview, current models, and considerations for future developments. Ecol Model 222:2178-2190

Fijen TPM, Kamp J, Lameris TK et al (2015) Functions of extensive animal dung "pavements" around the nest of the Black Lark (Melanocorpypha yeltoniensis). The Auk 132:878-892

Flaspohler DJ, Temple S, Rosenfield RN, Rosenfieldt RN (2007) Effects of forest edges on ovenbird demography in a managed forest landscape. Conserv Biol 15:173-183

Gilroy JJ, Sutherland WJ (2007) Beyond ecological traps: perceptual errors and undervalued resources. Trends Ecol Evol 22:351-356

Glutz von Blotzheim UN, Bauer KM (1985) Handbuch der Vögel Mitteleuropas, Band 10/I. Aula-verlag, Wiesbaden (In German)

Green RE, Cornell SJ, Scharlemann JPW, Balmford A (2005) Farming and the fate of wild nature. Science 307:550-555

Grömping U (2009) Variable importance assessment in regression: linear regression versus Random forest. Am Stat 63:308-319

Hoyt DF (1979) Practical methods of estimating volume and fresh weight of bird eggs. Auk 96:73-77

Ibáñez-Álamo JD, Sanllorente O, Soler M (2012) The impact of researcher disturbance on nest predation rates: a meta-analysis. Ibis $154: 5-14$

Kamp J, Urazaliev R, Donald PF, Hölzel N (2011) Post-Soviet agricultural change predicts future declines after recent recovery in Eurasian steppe bird populations. Biol Conserv 144:2607-2614

Kamp J, Siderova TV, Salemgareev AR et al (2012) Niche separation of larks (Alaudidae) and agricultural change on the drylands of the former Soviet Union. Agric Ecosyst Environ 155:41-49

Kazakhstan State Statistics Agency (2014) Agricultural statistics. Committee on statistics, Astana. http:// www.statgov.kz. Accessed 17 Sep 2015

Kleijn D, Berendse F, Smit R, Gilissen N, Smit J, Brak B, Groeneveld R (2004) Ecological effectiveness of agri-environment schemes in different agricultural landscapes in The Netherlands. Conserv Biol 18:775-786

Kleijn D, Baquero RA, Clough Y et al (2006) Mixed biodiversity benefits of argi-environment schemes in five European countries. Ecol Lett 9:243-254

Kokko H, Sutherland WJ (2001) Ecological traps in changing environments: ecological and evolutionary consequences of a behaviourally mediated Allee effect. Evol Ecol Res 3:537-551

Kraemer R, Prishchepov AV, Müller D et al (2015) Long-term agricultural land-cover change and potential for cropland expansion in the former Virgin Lands area of Kazakhstan. Environ Res Lett 10:054012

Krivitskii IA (2007) Notes on the biology of the Black Lark Melanocorypha yeltoniensis. Selevinia 15:131-137

Laake J, Rexstad E (2008) RMark-an alternative approach to building linear models in MARK. In: Cooch E, White G (ed) Program MARK: a gentle introduction. http://www.phidot.org/software/mark/docs/ book/ Accessed 17 Sep 2015

Liaw A, Wiener M (2002) Classification and regression by Random forest. R news 2:18-22. doi:10.1177/ 154405910408300516

Manthey M, Peper J (2010) Estimation of grazing intensity along grazing gradients-the bias of nonlinearity. J Arid Environ 74:1351-1354

Martin TE (1993) Nest predation among vegetation layers and habitat types: revising the dogmas. Am Nat 141:897-913

Mayfield H (1961) Nesting success calculated from exposure. Wilson Bull 73:255-261

Moiseev AP (1980) On the breeding biology of the Black Lark in Central and North Kazakhstah. In: Kovshar AF (ed) Biology of birds in the Naurzum National park. Nauka publishers, Almaty, pp 120-126 (In Russian) 
Morgado R, Beja P, Reino L et al (2010) Calandra lark habitat selection: strong fragmentation effects in a grassland specialist. Acta Oecol 36:63-73

Morris DL, Faaborg J, Washburn BE, Millspaugh JJ (2015) Predator-induced renesting and reproductive effort in indigo buntings: more work for less pay? Conserv Physiol. doi:10.1093/conphys/cou063

Nagelkerke NJD (1991) A note on a general definition of the coefficient of determination. Biometrika 78:691-692

Nakazawa M, Nakazawa MM (2014) Package 'fmsb'. R package. https://cran.r-project.org/web/packages/ fmsb/fmsb.pdf Accessed 20 Sep 2015

Noguerales V, Traba J, Mata C, Morales MB (2015) Winter habitat selection and partitioning in two sympatric farmland small mammals: apodemus sylvaticus and Mus spretus. Rev Ecol (Terre et Vie) 70:70-82

Pärt T, Wretenberg J (2002) Do artificial nests reveal relative nest predation risk for real nests? Oikos 33:39-46

Petrick M, Wandel J, Karsten K (2013) Rediscovering the Virgin Lands: agricultural investment and rural livelihoods in a Eurasian frontier area. World Dev 43:164-179

Pulliam HR (1998) Sources, sinks, and population regulation. Am Nat 132:652-661

Remes V (2000) How can maladaptive habitat choice generate population dynamics? Oikos 91:579-582

R Development Core Team (2015) R: A language and environment for statistical computing. https://www.rproject.org/ Accessed 17 Sep 2015

Robin X, Turck N, Hainard A et al (2011) pROC: an open-source package for R and S+ to analyze and compare ROC curves. BMC Bioinform 12:77

Robinson S, Milner-Gulland EJ (2003) political change and factors limiting numbers of wild and domestic ungulates in Kazakhstan. Hum Ecol 31:87-110

Rotella JJ, Dinsmore SJ, Shaffer TL (2004) Modeling nest-survival data: a comparison of recently developed methods that can be implemented in MARK and SAS. Anim Biodivers Conserv 27:187-205

Royle JA, Dawson DK, Bates S (2004) Modeling abundance effects in distance sampling. Ecology $85: 1591-1597$

Ryabov VF (1967) The foraging ecology of the Black Lark in the steppes of Northern Kazakhstan. Trudy Marijskogo Pedagogicheskogo Institutat 5:18-22 (In Russian)

Sabo JL, Bastow JL, Power ME (2002) Length-mass relationships for adult aquatic and terrestrial invertebrates in a California watershed. J N Am Benth Soc 21:336-343

Schlaepfer MA, Runge MC, Sherman PW (2002) Ecological and evolutionary traps. Trends Ecol Evol $17: 474-480$

Seoane J, Justribó JH, García F et al (2006) Habitat-suitability modelling to assess the effects of land-use changes on Dupont's lark Chersophilus duponti: a case study in the Layna Important Bird Area. Biol Conserv 128:241-252

Sinclair ARE, Pech RP (1996) Density dependence, compensation predator regulation. Oikos 75:164-173

Sofaer HR, Chapman PL, Sillett TS, Ghalambor CK (2013) Advantages of nonlinear mixed models for fitting avian growth curves. J Avian Biol 44:469-478

Stubben C, Milligan B, Nantel P (2008) Popbio: construction and analysis of matrix population models. R Foundation for Statistical Computing, Vienna. https://cran.r-project.org/web/packages/popbio/ popbio.pdf. Accessed 17 Sep 2015

Stumpp M, Wesche K, Retzer V, Miehe G (2005) Impact of grazing livestock and distance from water source on soil fertility in Southern Mongolia. Mt Res Dev 25:244-251

Suhonen J, Norrdahl K, Korpimaki E (1994) Avian predation risk modifies breeding bird community on a farmland area. Ecology 75:1626-1634

Suleimenov M, Oram P (2000) Trends in feed, livestock production, and rangelands during the transition period in three Central Asian countries. Food Policy 25:681-700

Urazaliev RS, Iskakov T, Kamp J (2012) Aggressive intraspecific behaviour among male Black Larks in winter. Br Birds 105:37

Volchanetskii IV (1954) Steppe Larks Melanocorypha (Boie 1828). In: Dementiev GP, Gladkov NA (eds) Birds of the Soviet Union, Vol.5. Moscow. pp 563-582 (In Russian)

Watkinson AR, Sutherland WJ (1995) Sources, sinks and pseudo-sinks. J Anim Ecol 64:126-130

White GC, Burnham KP (1999) Program MARK: survival estimation from populations of marked animals. Bird Study 46:S120-S139

Zuur A, Ieno EN, Walker N, Savaliev AA, Smith GM (2009) Mixed effects models and extensions in ecology with R. Springer, New York 